\title{
Does the Finding of Small Airway Obstruction in Pulmonary Function Tests Effect End-Expiratory Carbonmonoxide Level?
}

\author{
Banu Musaffa Salepçi, Ali Fidan, Elif Torun Parmaksız, Esma Coşkun, \\ Nesrin Kıral, Benan Çağlayan, Sevda Şener Cömert, Coşkun Doğan
}

Clinic of Chest Diseases, Dr. Lütfi Kırdar Kartal Training and Research Hospital, İstanbul

\begin{abstract}
Objective: End-expiratory CO level, which is used to test smoking cessation is known to be effected by many factors. We aimed to evaluate effect of small airway obstruction (SAO) on end-expiratory CO levels.

Methods: The study population consisted of cases who applied to smoking cessation clinic between April-December 2014. The duration of smoking (pack-years), pulmonary function tests (PFT) and end-expiratory carbonmonoxide (CO) were noted at first visit. The cases were questioned for last time of smoking and amount of cigarettes they smoked within past 12 hours. Pearson correlation test was used to determine factors effecting CO levels.

Results: Mean age of 167 cases -112 male (67.1\%), 55 female (32.9\%) was 38.7 \pm 12.7 years. Mean duration of smoking was $23.3 \pm 16.4$ pack-years, mean CO level was $14.1 \pm 6.9 \mathrm{ppm}$, mean FEF25-75\% was 77.2 \pm 28.2 . Mean period elapsed after last cigarette was $1.5 \pm 1.8$ hours, mean number of cigarettes smoked within past 12 hours was $7.2 \pm 5.0$. SAO was found in 50 cases (34.1\%). Correlation analyses revealed that CO levels were correlated positively to duration of smoking and amount of cigarettes they smoked within past 12 hours ( $p=0.03, r=0.228 ; p=0.000$, $\mathrm{r}=0.511$, respectively) and negatively to the last time of smoking ( $\mathrm{p}=0.023, \mathrm{r}=0.176)$. SAO and in PFT was not correlated to CO level ( $\mathrm{p}>0.05)$.
\end{abstract}

Conclusion: End-expiratory $\mathrm{CO}$ level is closely related to duration of smoking, number of cigarettes smoked within past 12 hours and period elapsed after last cigarette. Presence of SAO does not seem to effect CO levels.

Keywords: End-expiratory carbonmonoxide level, small airway obstruction, smoking addiction

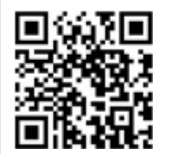

Received Date: 21.06 .2015 Accepted Date: 13.08 .2015 Available Online Date: 09.11.2015 DOI: 10.5152/ejp.2015.76476

Corresponding Author Banu Musaffa Salepçi E-mail: bsalepci@yahoo.com

-Available online at www.eurasianjpulmonol.com

This work is licensed under a Creative Commons Attribution-NonCommercial 4.0 International License.

\section{INTRODUCTION}

Carbon monoxide (CO) is one of the main substances that lead to air pollution and is the most commonly known substance among the 4500 chemicals included in a cigarette. $\mathrm{CO}$ is absorbed through smoking or can be produced endogenously in alveolar macrophages, endothelial cells, and other lung cells as a product of local inflammation and oxidative stress in individuals with airway diseases (1). In many studies, it was revealed that the end-expiratory $\mathrm{CO}$ (exhaled $\mathrm{CO}$ ) level was higher in patients with severe asthma and lower in asthma patients receiving inhaled steroid therapy than in those not having therapy (2-4). Therefore, the exhaled CO level has recently begun to be used as an inflammatory biomarker in airway diseases such as asthma, chronic obstructive pulmonary disease (COPD), cystic fibrosis, and bronchiectasis $(1,5)$. However, it was concluded in some studies that the exhaled CO level could not be used routinely as a biomarker in patients with asthma and cystic fibrosis because no relationship was found between the exhaled CO level and airflow limitations $(6,7)$.

The measurement of exhaled $\mathrm{CO}$ during patient follow-up in smoking cessation clinics has become an objective criterion for confirming smoking cessation and also increases patient compliance to treatment. In the differentiation of smokers from non-smokers, the cutoff value for exhaled $\mathrm{CO}$ is accepted to be 6 ppm $(8,9)$. In a study, the mean CO level was found to be $17 \mathrm{ppm}$ in healthy smokers, $3 \mathrm{ppm}$ in healthy non-smokers, and $5 \mathrm{ppm}$ in passive smokers (10). It was demonstrated in some studies that the number of cigarettes smoked per day, type of cigarette, duration of smoking, and method of smoking affected 
the exhaled CO level in active smokers (11-13). If active smokers do not smoke during the previous $8 \mathrm{~h}$, the exhaled $\mathrm{CO}$ level is found to be below $12 \mathrm{ppm}$ and the exhaled CO level is reduced by half every $4.3 \mathrm{~h}$ without smoking (13). If there is underlying an airway disease such as COPD or asthma in active smokers, exhaled CO level is suggested to be higher than expected (14). In other studies that suggest the opposite, it was detected that the exhaled CO level was related to the current level of smoking in COPD patients but did not exhibit a correlation with the severity of $\operatorname{COPD}(15,16)$. On the other hand, in a study of a large population, it was concluded that the exhaled CO level could not be an indicator of pulmonary functions (17).

Because of the contradictory results in the literature, in this study, it was aimed to investigate the effect of obstruction of the small airways, which was detected by spirometry and was an initial indicator of COPD, on the end-expiratory CO level in patients who applied to our smoking cessation clinic in the light of this information.

\section{METHODS}

Our study was a cross-sectional study.

\section{Cases}

All patients who applied to the smoking cessation clinic between April 2014 and December 2014 and who underwent a measurement of exhaled CO level and Pulmonary function tests (PFT) were included in the study. Patients who displayed noncompliance to the PFT were excluded from the study.

Written informed consent was obtained from patients for using their data. On admission, the amount of cigarettes smoked (pack-year) was determined in all patients. They were asked about how many cigarettes they had smoked within the last $12 \mathrm{~h}$ and about the last time they smoked.

\section{Spirometry}

This procedure was performed with a Sensor Medics Vmax 22 spirometry device (CareFusion, USA) by a nurse educated in pul- monary function testing in accordance with ATS/ERS (American Thoracic Society/European Respiratory Society) standard rules for spirometry (18), when the patient was in a sitting position. The results of spirometry were evaluated by the same physician who had first met the patient in the outpatient clinic and FEF25-75\% levels were recorded. If the FEF $25-75 \%$ level was decreased by $65 \%$ from the expected level, this was accepted as being due to small-airway obstruction (SAO) (19).

\section{Measurement of End-Expiratory Carbon Monoxide Level}

The same research physician performed measurements of exhaled CO with a CO monitor (Bedfont Pico Smokerlyzer, coVita, Washington, USA), when the patient was in a sitting position. The patient breathed deeply and held his/her breath for $15 \mathrm{~s}$. Then, expiration was performed slowly and deeply with a mouthpiece and exhaled $\mathrm{CO}$ levels were measured. Finally, the results were recorded as ppm.

All data were transferred to the recording system of the hospital.

\section{Statistical Analysis}

Data were analyzed using the Statistical Package for the Social Sciences (SPSS Inc.; Chicago, IL, USA) version 17.0 software. When comparing patients with and without $\mathrm{SAO}$, the chi-square test and Fisher's exact test were used for categorical variables. Student's t-test was employed for numerical variables. For the detection of a relationship between the CO level and effective factors, Pearson's correlation analysis was performed. A value of $p<0.05$ was used to indicate statistical significance.

\section{RESULTS}

The mean age of 167 patients was $38.7 \pm 12.7$ years. In total, 112 patients $(67.1 \%)$ were male and 55 (32.9\%) were female. The mean amount of cigarettes smoked was $23.3 \pm 16.4$ pack-year. The mean end-expiratory CO level was found to be $14.1 \pm 6.9 \mathrm{ppm}$. In the PFT, the mean FEF25-75\% level was $77.2 \pm 28.2$. Within the previous 12 $h$ of patients, the time that elapsed from the last cigarette until the

Table 1. Demographic features and Pulmonary function tests values of patients

\begin{tabular}{|c|c|c|c|c|}
\hline & All cases $n=167$ & $\begin{array}{c}\text { Patients with SAO } \\
n=57(34.1 \%)\end{array}$ & $\begin{array}{c}\text { Patients without SAO } \\
n=110(65.9 \%)\end{array}$ & $p$ \\
\hline Age (years) & $38.7 \pm 12.2$ & $47.0 \pm 12.4$ & $34.3 \pm 9.6$ & $<0.001$ \\
\hline Gender, Male \% & 67.1 & 57.8 & 71.8 & \\
\hline Female $\%$ & 32.9 & 42.2 & 28.2 & 0.083 \\
\hline Fagerstrom score & $6.1 \pm 2.5$ & $6.0 \pm 2.4$ & $6.2 \pm 2.6$ & 0.484 \\
\hline Amount of smoking (pack-year) & $23.3 \pm 16.4$ & $31.9 \pm 19.3$ & $18.8 \pm 12.7$ & $<0.001$ \\
\hline Exhaled CO level (ppm) & $14.1 \pm 6.9$ & $14.1 \pm 6.2$ & $14.1 \pm 7.3$ & 0.984 \\
\hline Last time of smoking (h) & $1.5 \pm 1.8$ & $1.3 \pm 0.7$ & $1.7 \pm 2.2$ & 0.208 \\
\hline Number of cigarettes & $7.0 \pm 4.7$ & $7.0 \pm 4.1$ & $7.1 \pm 5.0$ & 0.915 \\
\hline FVC \% & $96.3 \pm 14.9$ & $92.3 \pm 15.9$ & $101.8 \pm 12.1$ & $<0.001$ \\
\hline $\mathrm{FEV}_{1} \%$ & $92.8 \pm 15.8$ & $78.0 \pm 13.6$ & $100.5 \pm 10.4$ & $<0.001$ \\
\hline $\mathrm{FEV}_{1} / \mathrm{FVC}$ & $80.0 \pm 10.9$ & $71.0 \pm 9.2$ & $84.6 \pm 8.5$ & $<0.001$ \\
\hline FEF $25-75 \%$ & $77.2 \pm 28.2$ & $48.7 \pm 13.6$ & $92.5 \pm 21.3$ & $<0.001$ \\
\hline
\end{tabular}




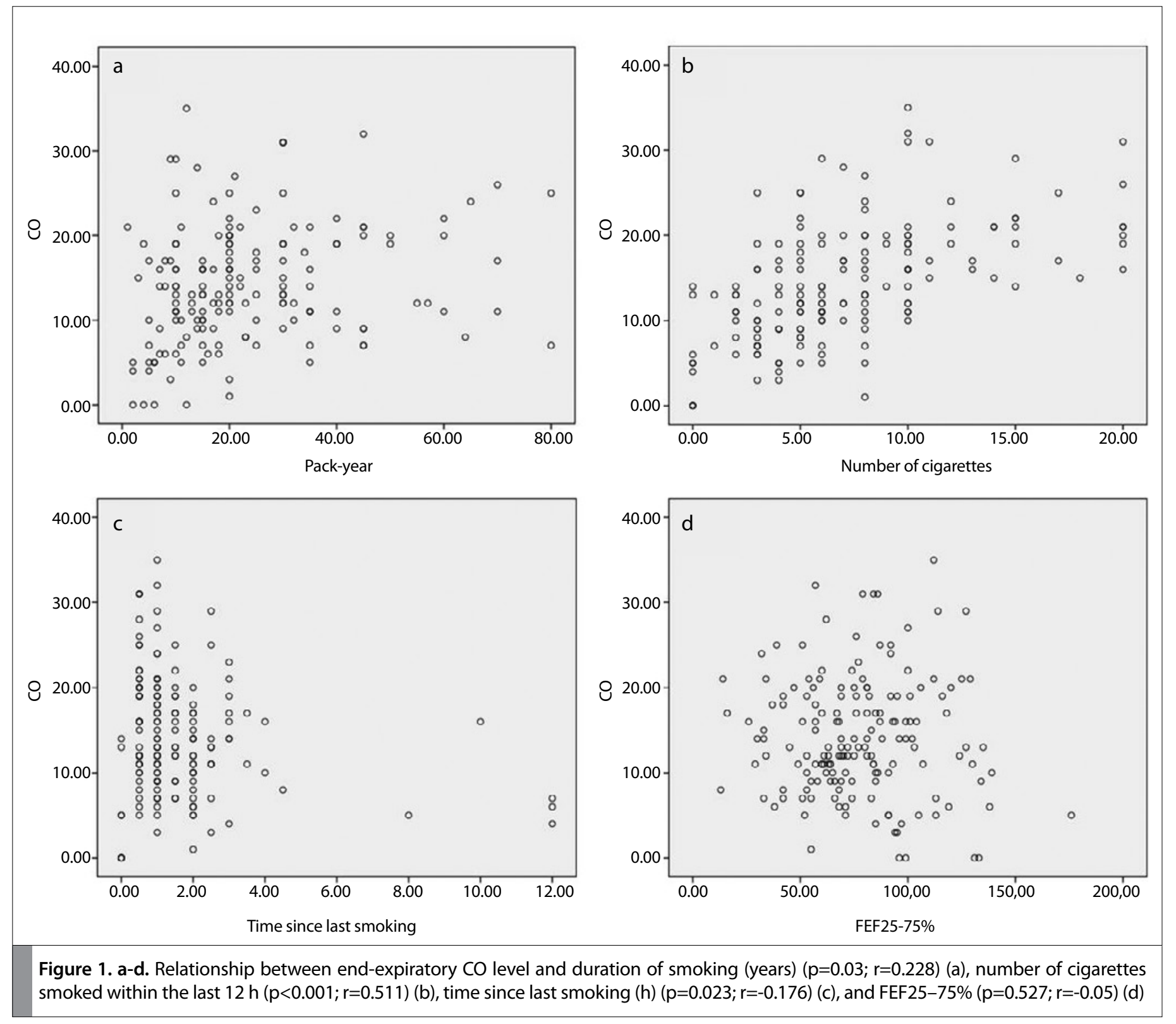

measurement of the $\mathrm{CO}$ level was $1.5 \pm 1.8 \mathrm{~h}$ and the mean number of cigarettes was $7 \pm 4.7$ (Table 1 ).

The PFT revealed SAO in 57 patients (34.1\%). The mean age was higher in cases with SAO than in those without SAO (47 and 34.3 years, respectively; $p<0.001$ ), and the amount of cigarettes smoked (packyear) was also significantly higher (31.9 and 18.8 pack-year, respectively; $p<0.001)$. There was no difference with respect to the mean exhaled CO level, the number of cigarettes smoked last, or the time that elapsed from the last cigarette until the measurement of the $\mathrm{CO}$ level ( $p>0.05$ ). In the PFT, FEV 1 , FVC, FEV $/$ FVC, and FEF25-75 values were found to be significantly lower in patients with SAO $(p<0.001)$ (Table 1).

Of our patients, $8.9 \%$ had asthma and 3.6\% had COPD. There was no significant difference between patients with and without asthma in terms of their mean age (40.2 and 38.5 years, respectively), amount of cigarettes smoked (24.2 pack-year and 23.2 pack-year, respectively), or exhaled CO level ( $p>0.05$ ). The FEF $25-75 \%$ level was lower in asthma patients, but the difference was not statistically significant (69.5\% and $77.9 \%$, respectively; $p=0.287)$. In patients with COPD, age (59.6 and 37.9 years, respectively; $p<0.001$ ) and amount of cigarettes smoked (54.8 and 22.1 pack-year, respectively; $p<0.001$ ) were significantly higher, but the FEF25-75\% level was significantly lower than in patients without COPD $(31.1 \%$ and $78.9 \%$, respectively; $\mathrm{p}<0.001)$. However, no statistically significant difference was found in terms of exhaled CO level (13.5 ppm and 13.1 ppm, respectively; $p=0.895$ ).

Correlation analysis revealed a weak positive correlation between the exhaled CO level and amount of cigarettes smoked (pack-year) and a moderate positive correlation between the exhaled $\mathrm{CO}$ level and number of cigarettes smoked within the last $12 \mathrm{~h}(\mathrm{p}=0.03, r=0.228$; $p=0.000, r=0.511$, respectively) (Figure $1 a, b)$. A weak negative correlation was found between the exhaled $\mathrm{CO}$ level and the time that elapsed from the last cigarette until the measurement of the CO level $(p=0.023, r=-0.176)$ (Figure 1c). No correlation was detected between 
the presence of SAO, the FEF $25-75 \%$ level, and the exhaled CO level $(p=0.984, r=-0.02 ; p=0.527, r=-0.05)$ in the PFT (Figure $1 d)$.

\section{DISCUSSION}

In our study, SAO was detected in $34.1 \%$ of cases, and these patients were of advanced age and heavy smokers, as expected. End-expiratory CO levels were found to be correlated to frequency of smoking, number of cigarettes smoked within the last $12 \mathrm{~h}$, and the last time of smoking. No negative or positive correlation was detected between the presence of SAO, the FEF25-75\% level, and the exhaled CO level. In cases with asthma and COPD, exhaled CO levels were not different from those in healthy smokers.

Our study is important because it has contributed to the literature as an article that reports a negative result because no relationship was found between airway disease and the exhaled CO level. In other studies conducted on this issue, contradictory results have been reported.

Carbon monoxide is a chemical substance absorbed through smoking in smokers. In smoking cessation clinics, the end-expiratory CO level is measured in order to determine whether patients smoke or not during follow-ups and the cutoff value is accepted to be 6 ppm $(8,9)$. In the study of Deveci et al. (10), the mean exhaled CO level was found to be $17.1 \mathrm{ppm}$ in active smokers, $5.2 \mathrm{ppm}$ in passive smokers, and 3.6 ppm in non-smokers and the cutoff value for distinguishing smokers from non-smokers was identified to be $6.5 \mathrm{ppm}$. They also revealed a positive correlation between the exhaled $\mathrm{CO}$ level and the number of cigarettes per day and duration of smoking. In studies on the factors affecting the exhaled $\mathrm{CO}$ level in active smokers, the number of cigarettes per day, type of cigarette, method of smoking, and duration of smoking were found to be effective factors (11-13). In the study of Fabricius et al. (12), the exhaled CO level was found to be lower in individuals who smoked unfiltered cigarettes and did not inhale smoke. In another study, the exhaled CO level was found to be lower than 12 ppm in people who had not smoked within the previous $8 \mathrm{~h}$ and the level of exhaled CO reduced by half every $4.3 \mathrm{~h}$ without smoking (13). In our study, the type of cigarette and the method of smoking were not investigated, which was a limitation of the study. However, the number of cigarettes smoked within the previous $12 \mathrm{~h}$ and the time of last smoking were determined. It was observed that the exhaled CO level displayed a positive correlation with the number of cigarettes and a negative correlation with the time that elapsed after the last cigarette. Similarly to our study, Cunnington and Hormbrey (20) found a positive relationship between the exhaled $\mathrm{CO}$ level and the number of cigarettes and a negative relationship between the exhaled $\mathrm{CO}$ level and the time that elapsed after the last cigarette. There are also older studies that report the same results $(21,22)$. Moreover, a positive correlation was detected between the amount of cigarettes smoked (packs/ year) and the exhaled CO level in our study.

Studies that show a relationship between the CO level and pulmonary tract diseases and the results of PFTs have been seen since 2000 . In two studies conducted by a Japanese group, the exhaled CO level was found to be higher in patients with asthma than in healthy individuals $(2,3)$. In a meta-analysis that also referred to two studies conducted in Turkey $(23,24)$, it was reported that the exhaled CO level was found to be higher in asthma patients who did not smoke than in those without asthma, and the CO level displayed a correla- tion with the severity of asthma (4). Jesenak et al. (5) stated that the exhaled CO level could be used as a biological marker for allergic inflammation and oxidative stress in asthmatic children (5). However, there are two studies that show the opposite, in which no relationship was demonstrated between airflow limitations and the exhaled CO level in patients with asthma and cystic fibrosis $(6,7)$. In our study, no statistically significant difference was found between the exhaled CO level measured in asthma and COPD patients and the exhaled $\mathrm{CO}$ level measured in individuals without airway diseases. This result might have been obtained because all our patients were smokers and we did not have a control group. On the other hand, in the study of Sato et al. (14), which was different from our study, the exhaled CO level was found to be higher than expected in smokers with asthma and COPD. The cutoff values for exhaled CO between smokers and non-smokers were found to be $10 \mathrm{ppm}$ in asthma cases and $11 \mathrm{ppm}$ in COPD cases, which were higher than the accepted cutoff value of $6 \mathrm{ppm}$. It was concluded that underlying airway disease might be misleading for distinguishing smokers from non-smokers. However, as in our study, there are some studies that show that the exhaled CO level is not related to COPD but to the state of smoking in COPD patients $(15,16)$. In one of these studies, Montuschi et al. $(16)$ found that the exhaled CO level was significantly higher in smokers with COPD than in non-smokers with COPD and they could not demonstrate a relationship between the exhaled $\mathrm{CO}$ level and pulmonary functions. They concluded that the exhaled $\mathrm{CO}$ level was correlated with the state of smoking and that therefore it could not be used as a biomarker of inflammation in patients with COPD.

In the study of Fabricius et al. (17) on a large population, a positive correlation was reported between smokers' existing $\mathrm{FEV}_{1} \%$ level, decrease in $\mathrm{FEV}_{1}$ over time, and exhaled $\mathrm{CO}$ level, but linear regression analysis revealed this correlation to be insignificant. It was concluded that the most important factors that affected the exhaled CO level were the type of cigarette and the method of smoking. In our study, no correlation was found between the exhaled $\mathrm{CO}$ level, the presence of SAO, and FEF $25-75 \%$ values.

One of the limitations of our study was that the type of cigarette and method of smoking were not investigated. Another was the absence of a control group that included non-smokers. Therefore, no comparison was made between non-smoking SAO patients and smoking SAO patients.

\section{CONCLUSION}

In our study, end-expiratory CO levels in patients with asthma and COPD were not found to be different from the levels in smokers without any airway disease. Furthermore, no relationship was found between SAO, FEF25-75\% levels, and the exhaled CO level. The amount of cigarettes smoked, the number of cigarettes smoked within the last $12 \mathrm{~h}$, and the time that elapsed after the last cigarette were determined to be the factors that affected the exhaled CO level. It is suggested that further studies with larger populations and with a control group consisting of non-smokers should be performed on this issue.

Ethics Committee Approval: Ethics committee approval was not obtained. Because pulmonary function test and measurement of carbonmonoxide level in expired air are routin procedure in our smoking cessation outpatient clinic.

Informed Consent: Written informed consent was not obtained from patients who participated in this study. Because pulmonary function test and mea- 
surement of carbonmonoxide level in expired air are routin procedure in our smoking cessation outpatient clinic.

Peer-review: Externally peer-reviewed.

Author Contributions: Concept - B.M.S.; Design - B.M.S., A.F.; Supervision B.Ç.; Resource - B.Ç., A.F.; Materials - E.C., C.D., ; Data Collection and/or Processing - B.S., E.T.P., N.K.; Analysis and/or Interpretation - A.F., B.S.; Literature Search - S.Ş.C., N.K.; Writer - B.S., E.T.P.; Critical Review - B.Ç., B.S.; Other - E.C.

Conflict of Interest: No conflict of interest was declared by the authors.

Financial Disclosure: The authors declared that this study has received no financial support.

\section{REFERENCES}

1. Ryter SW, Choi AM. Carbon monoxide in exhaled breath testing and therapeutics. J Breath Res 2013; 7: 017111. [CrossRef]

2. Zayasu K, Sekizawa K, Okinaga S, Yamaya M, Ohrui T, Sasaki H. Increased carbon monoxide in exhaled air of asthmatic patients. Am J Respir Crit Care Med 1997; 156: 1140-3. [CrossRef]

3. Yamaya M, Hosoda M, Ishizuka S, Monma M, Matsui T, Suzuki T, et al. Relation between exhaled carbon monoxide levels and clinical severity of asthma. Clin Exp Allergy 2001; 31:417-22. [CrossRef]

4. Zhang J, Yao X, Yu R, Bai J, Sun Y, Huang M, et al. Exhaled carbon monoxide in asthmatics: a meta-analysis. Respir Res 2010; 11: 50. [CrossRef]

5. Jesenak M, Banovcin P, Havlicekova Z, Dobrota D, Babusikova E. Factors influencing the levels of exhaled carbon monoxide in asthmatic children. J Asthma 2014; 51: 900-6. [CrossRef]

6. Zetterquist W, Marteus H, Johannesson M, Nordval SL, Ihre E, Lundberg JO, et al. Exhaled carbon monoxide is not elevated in patients with asthma or cystic fibrosis. Eur Respir J 2002; 20: 92-9. [CrossRef]

7. Beck-Ripp J, Latzin P, Griese M. Exhaled carbon monoxide is not flow dependent in children with cystic fibrosis and asthma. Eur J Med Res 2004; 9 : 518-22.

8. Jamrozik K, Vessey M, Fowler G, Wald N, Parker G, Van Vunakis H. Controlled trial of three different anti-smoking interventions in general practice. Br Med J 1984; 288: 1499-502. [CrossRef]

9. Middleton ET, Morice AH. Breath carbon monoxide as an indication of smoking habit. Chest 2000; 117: 758-63. [CrossRef]

10. Deveci SE, Deveci F, Acik Y, Ozan AT. The measurement of exhaled carbon monoxide in healthy smokers and non-smokers. Respir Med 2004; 98: 551-6. [CrossRef]
11. Hung J, Lin CH, Wang JD, Chan CC. Exhaled carbon monoxide level as an indicator of cigarette consumption in a workplace cessation program in Taiwan. J Formos Med Assoc 2006; 105: 210-3. [CrossRef]

12. Fabricius $\mathrm{P}$, Scharling $\mathrm{H}$, Lokke $\mathrm{A}$, Vestbo J, Lange P. Exhaled CO, a predictor of lung function? Respir Med 2007; 101: 581-6. [CrossRef]

13. Sandberg A, Sköld CM, Grunewald J, Eklund A, Wheelock ÅM. Assessing recent smoking status by measuring exhaled carbon monoxide levels. PLoS One 2011; 6: e28864. [CrossRef]

14. Sato S, Nishimura K, Koyama H, Tsukino M, Oga T, Hajiro T, et al. Optimal cutoff level of breath carbon monoxide for assessing smoking status in patients with asthma and COPD. Chest 2003; 124: 1749-54. [CrossRef]

15. Crowley TJ, Andrew AE, Cheney J, Zerbe G, Petty TL. Carbon monoxide assessment of smoking in chronic obstructive pulmonary disease. Addict Behav 1989; 19: 493-502. [CrossRef]

16. Montuschi P, Kharitonov SA, Barnes PJ. Exhaled carbon monoxide and nitric oxide in COPD. Chest 2001; 120: 496-501. [CrossRef]

17. Fabricius $\mathrm{P}$, Scharling $\mathrm{H}$, Lokke $A$, Vestbo J, Lange P. Exhaled CO, a predictor of lung function? Respir Med 2007; 101: 581-6. [CrossRef]

18. Celli BR, MacNee W and ATS / ERS committee members. ATS / ERS Task Force. Standarts for the diagnosis and treatment of patients with COPD: a summary of the ATS / ERS position paper. Eur Respir J 2004; 23: 932-46. [CrossRef]

19. Ciprandi G, Capasso M, Tosca M, Salpietro C, Salpietro A, Marseglia G, et al. A forced expiratory flow at $25-75 \%$ value $<65 \%$ of predicted should be considered abnormal: a real-world, cross-sectional study. Allergy Asthma Proc 2012; 33: e5-8. [CrossRef]

20. Cunnington AJ, Hormbrey P. Breath analysis to detect recent exposure to carbon monoxide. Postgrad Med J 2002; 78: 233-8. [CrossRef]

21. Henningfield JE, Stitzer ML, Griffiths RR. Expired air carbon monoxide accumulation and elimination as a function of number of cigarettes smoked. Add Behav 1980; 5: 265-72. [CrossRef]

22. Rees PJ, Chilvers C, ClarkTJH. Evaluation of methods used to estimate inhaled dose of carbon monoxide. Thorax 1980; 35: 47-51. [CrossRef]

23. Yilmaz O, Ozturk F, Bakirtas A, Cengizlier R, Turktas I. Exhaled carbon monoxide levels in children with bronchial asthma. Pediatric Asthma, Allergy and Immunology 2003; 16: 155-62. [CrossRef]

24. Ece A, Gürkan F, Haspolat K, Derman O, Kirbas G. Passive smoking and expired carbon monoxide concentrations in healthy and asthmatic children. Allergol Immunopathol 2000; 28: 255-60. 